\title{
Euroson Courses
}
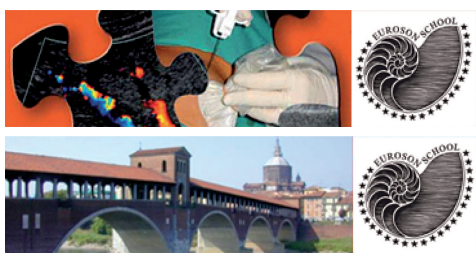

EUROSON SCHOOL - Bologna, Italy

International Course of Ultrasound in

Gastroenterology and Hepatology

10th - 12th September 2012

EUROSON SCHOOL - Pavia, Italy

2nd SonoElastography International Meeting 3rd - 5th October 2012

There are still places available on both these courses, full programmes and registration forms can be found on www.efsumb.org
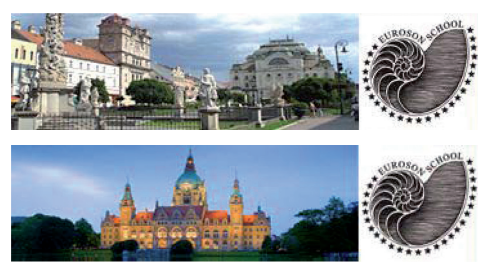

EUROSON SCHOOL

Košice, Slovakia CEUS Course 12th - 13th October 2012

Book now for the CEUS Courses on www.efsumb.org Košice $€ 150$ for 1.5 days

CEUS Part 1 in Hannover, Germany - Liver, Biliary System and Kidney €500 for 3.5 days www.ceus-course.eu 